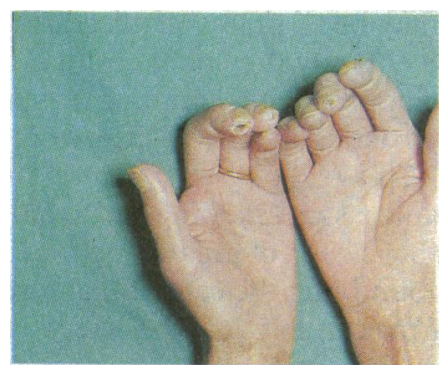

Severe Raynaud's phenomenon can result in ulceration of the finger tips.
Digital ulceration or gangrene may also be caused by non-vasospastic conditions. Emboli may be discharged from the fibrillating atrium, the ventricle after a myocardial infarction, or from an aneurysm of the subclavian artery. Arteriovenous malformations in the hand can cause enough shunting of blood to result in distal ischaemia. Occasionally, thrombotic disorders such as polycythaemia or thrombocythaemia may cause digital ischaemia, but this is most unusual in the hand.

Vascutherm gloves are distributed by Camp Ltd, Worcester. We acknowledge with thanks the assistance of the audiovisual department, St Mary's Hospital, London, in the preparation of the illustrations.

M H Grigg, FRACs, is senior lecturer in surgery, Alfred Hospital, Melbourne, Australia, and Mr John H N Wolfe, FRCS, is consultant vascular surgeon at St Mary's Hospital, London.

The $A B C$ of Vascular Diseases has been edited by Mr John $\mathrm{H}$ N Wolfe.

\title{
Manpower and hours of work agreements are complementary
}

\author{
Paul D Miller
}

This is the second in a series of articles which explore the new deal on junior doctors' hours of work and explain how it will be implemented.

Watford General Hospital, Watford, Hertfordshire WD1 8HB

Paul D Miller, MRCPSYCH, research registrar in psychiatry

BMF 1991;303:916-8
In the mid-1980s Achieving a Balance and Plan for Action aimed to address the problems of the hospital career structure. ${ }^{12}$ The ratio of junior doctors to consultants was and has remained approximately three to two. This has caused severe bottlenecks. For a medical graduate to spend no more than 10 to 11 years in training followed by 25 to 30 years as a consultant the ratio needs to drop to one to two and a half.

In 1988-9 3467 doctors graduated from British medical schools; fewer than half (1577 born in the United Kingdom or Ireland) entered general practice. But between 1981 and 1989 an average of only 331 new consultant posts were created each year. The consultant retirement rate is under 600 a year, and although consultant expansion increased towards the end of the 1980 s, total opportunities in 1987-8 and 1988-9 were still only approximately 1000 posts a year.

Achieving a Balance introduced the concept of career and visiting registrars. A career registrar is a United Kingdom or European Communities doctor who is entitled to pursue a career in Britain. A visiting registrar is an overseas doctor who is expected to return home after training. It was agreed that the number of career registrars and senior registrars in all specialties would be adjusted to the number required to fill the expected number of consultant opportunities. If the career registrar quota was lower than the current number of registrars any shortfall could be made up by visiting registrars. So Achieving a Balance does not necessarily require any reduction in the total number of registrars.

Implicit in the agreement is the acceptance that many registrar posts are not training posts but fulfil a service need which should be performed by consultants or staff grade doctors; other registrars would be more appropriately replaced by senior house officers. The quotas issued by the Joint Planning Advisory Committee (JPAC) do not hinder career prospects, but make career prospects clearer by removing the false promise of dead end posts which might previously have been designated as registrar posts. If there are only 100 consultant opportunities a year in a specialty it is wasteful to train 200 registrars each year.

Under Achieving a Balance appointment to a career registrar post should normally be a good indicator that there would be a consultant post available when the doctor has completed training. Just as importantly, doctors who cannot obtain career registrar posts in their chosen specialty should be able to reconsider their career options in their mid-20s when they are senior house officers and not in their late 30s when they are already senior registrars with little chance of achieving a consultant post. Achieving a Balance introduced 100 extra consultant posts, an early retirement scheme for consultants (which has since been extended to associate specialists), and mechanisms for converting registrar and senior registrar posts surplus to training requirements to consultant posts. The Department of Health has now issued quotas for senior registrar and registrar posts, based on the best available manpower data, to be achieved by $1992-4$ for senior registrars and 2000 for registrars. ${ }^{3}$

\section{On to the next step}

Once agreement had been reached on Achieving $a$ Balance and the necessary mechanisms for implementation had been established attention turned to the problem of the excessive hours being worked by junior doctors and the difficulties and inconveniences caused by the gradual erosion of their conditions of service, such as the deterioration of doctors' messes and on call facilities.

Despite being told that their hours had markedly improved and that onerous rotas were being phased out most junior doctors knew that this was not true. At a time when the average working week was about 38 hours it was not difficult to find juniors on one in two rotas or on one in three rotas with prospective cover working 136 hours a week. These anecdotes were supported by the Dowie report which demonstrated an increase in hours of duty between 1985 and 1987-8, with the average junior doctor being on duty for 90 hours a week. ${ }^{4}$ These doctors are also expected to study for postgraduate qualifications and research projects which are necessary for advancing their careers. This leaves little time for families, social life, or recreational interests.

After a long campaign by the BMA's Hospital Junior Staff Committee (HJSC) and other groups including 
sleeping outside hospitals at Christmas, attempts at legislation and legal action, and much media publicity a ministerial working party was set up in 1990 . This was chaired by the Minister for Health, Mrs Virginia Bottomley, and included representatives of junior doctors, consultants, the medical royal colleges, NHS management, and the United Kingdom health departments. In December 1990 the working party published the heads of agreement, a package of measures aimed at establishing a maximum average working week for all junior doctors of 72 hours and at improving juniors' conditions of work. The measures included targeted consultant expansion with separately identified central funding, delegation of appropriate work to other staff groups, a change to the use of consultant teams and cross cover, and the introduction of shift working by junior doctors. Though it is easy to find faults with Achieving a Balance and the heads of agreement, the problems are soluble, given sufficient commitment from all parties and resources from the government.

\section{... the problems are soluble, given sufficient commitment from all parties and resources from the government.}

Can juniors look forward to a well planned career structure, substantially reduced hours, and improved conditions while on call? It would not be surprising if many junior doctors remained sceptical. After all, almost five years after Achieving a Balance was published the process of adjusting registrar quotas has only just begun. This, however, would be to ignore the 100 extra consultants, substantial numbers of senior registrars, 96 early retirements, and the introduction of the staff grade.

\section{Problems and solutions}

The main outcome of Achieving a Balance-that is, the setting up of appropriate registrar and senior registrar quotas by the JPAC-may be thought to be a simple task of identifying those doctors who have a good chance of career progress. But if consultant expansion is inadequate the number of trainees permitted under this formula may seem unacceptably small to meet service needs. The answer is to boost consultant expansion and this is why a carefully targeted increase in consultant numbers was announced as part of the hours of work agreement.

The early retirement scheme has been taken up by 96 consultants in the first two years-a lower figure than anticipated. This is probably due to employing authorities' unwillingness to bear the financial consequences. The limit for early retirements of consultants and associate specialists in 1991-2 is 115 and the scheme may require some review if the take up continues at the same low rate.

In order for there to be improvements in hours of work there must be pressure for change at local level as well as for national bodies to remain committed. The regional task forces will have a crucial role to play, but the HJSC believes that general managers' contracts should include an incentive to reduce juniors' hours by linking it to their performance related pay.

What is the interaction between the manpower and hours of work agreements? It is often said that it simply requires more juniors and an abandonment of the current manpower controls to reduce juniors' hours. This is not so. If new consultants are appointed over the next few years to take on appropriate consultant work, which is currently being done by juniors, and at the same time the non-medical and non-educational work currently done by junior doctors is transferred to other staff the average workload of juniors will fall. This will allow an increase in cross cover and a decrease in the number of doctors on duty at any one time. Combined with the introduction of shift and partial shift systems, the required reduction in hours will be achieved easily within current manpower constraints.

It has been suggested that training will need to be extended if hours are reduced. But the royal colleges have agreed that 72 hours is sufficient for training, and that posts with longer hours might not be recognised as training posts with educational approval.

Given the benefits which will flow from the successful implementation of Achieving a Balance and the heads of agreement will there be enough trained doctors to take up the extra consultant posts? The proposed increase might require an early revision of the JPAC's quotas. Fortunately, the figures used by the committee in arriving at quotas were mostly optimistic estimates of future consultant expansion and assume an indefinite overall growth rate of $3 \cdot 5 \%$. The actual growth rate achieved from 1985-9, including all the measures agreed in Achieving a Balance, was $2.5 \%$. Two hundred extra consultant posts a year adds $1 \cdot 3 \%$ to the growth rate, although the effects in some specialties will be greater than in others.

\section{Too many career registrars}

There will continue to be an excess of career registrars over the ten years covered by the JPAC quotas. ${ }^{6}$ The excess in oversupplied specialties is more than 1200 doctors, while only 242 posts will be created over the baseline number in undersupplied specialties. In other words, there is an excess of over 1000 career registrars in the system at present. In contrast, at senior registrar level, only about 100 posts need to be reduced, and over 550 of the total number of posts approved by the JPAC are unoccupied. Nearly half this number are in anaesthetics and psychiatry.

The specialties most likely to be targeted for expansion are those where the problem is most acute: paediatrics, obstetrics and gynaecology, anaesthetics, and other medical and surgical specialties. With the exception of paediatrics all have an excess of career registrars. At senior registrar level there are over 200 unfilled posts in paediatrics, anaesthetics, geriatric medicine, and traumatic and orthopaedic surgery, but the other specialties have a negligible senior registrar vacancy rate. If all the vacant senior registrar posts were filled by promoting some of the excess registrars there would still be an excess of career registrars in all specialties except paediatrics. For example, general surgery has a career registrar excess equal to over six years of consultant opportunities in general surgery at current expansion and retirement rates. The excess in the general medical group of specialties is almost three years. This means that instead of drastically reducing registrar recruitment or forcing registrars to leave a specialty after several years' experience the opportunity now exists to promote a much larger than expected number of senior registrars to consultant posts, so enabling those in the registrar bulge to find senior registrar posts. This will enable these registrars to pursue their chosen career and maintain manpower controls.

It will be vital to examine in detail the manpower consequences of the proposed increase in consultant numbers and to see whether the registrar and senior registrar quotas need to be revised. Initial consideration of the data, however, suggests that career registrar quotas would need little upward adjustment unless consultant expansion is boosted even further than the current agreed level. None the less, although the JPAC normally reviews specialties at least every three years, 
it may be necessary to review earlier and more often those specialties which benefit most from the increased consultant expansion.

At senior registrar level the picture is different. Indeed, because there is no bulge of excess post holders in the specialties likely to be affected there may be grounds for concern about the supply of adequately trained senior registrars. It also seems likely that a disproportionate number of these senior registrars have been appointed within the last year and so will not be seeking consultant posts for nearly three years.

\section{Far from being incompatible the manpower and hours of work agreements are capable of working well together. ...}

There may therefore need to be an increase in senior registrar quotas in some specialties if the extra expansion is to continue for several years. On the other hand, the figures assumed by the JPAC for consultant expansion were rather optimistic. The data available suggest that the senior registrar quotas already set will provide about 100 fully trained senior registrars a year more than the average annual number of consultant opportunities in the medical and surgical specialties, paediatrics, anaesthetics, obstetrics and gynaecology, and accident and emergency.

\section{Success with resources and political will}

Far from being incompatible the manpower and hours of work agreements are capable of working well together; they are complementary and even synergistic.
The prospect of a rolling programme of consultant expansion should not be a major manpower problem; it offers the possibility of solving the problem of the career registrar excess while at the same time opens up career prospects for the hundreds of doctors who make up the bulge. At the time of the Achieving a Balance agreement many junior doctors thought that a $2 \%$ consultant expansion rate was insufficient for the plan to work. It now seems possible that by the start of the next century with sufficient resources and political will junior doctors will be able to enjoy a career structure balance, with the prospect of a first permanent job in their early to mid-30s, after 10 to 12 years spent working no more than 72 hours a week on average.

1 Department of Health and Social Security, Joint Consultants Committee, chairmen of regional health authorities. Hospital medical staffing: achieving balance. London: DHSS, 1986

2 Department of Health and Social Security, Joint Consultants Committee, chairmen of regional health authorities. Hospital medical staffing: achieving $a$ balance-plan for action. London: DHSS, 1987.

3 Department of Health. Foint planning advisory committee-definitive quotas for career registrars. London: DoH, 1990. $(\mathrm{EL}(90) \mathrm{P}(47)$.
cortent

4 Dowie R. Patterns of hospital medical staffing. Interim report: junior doctors' hours. London: British Postgraduate Medical Federation, 1989.

5 Department of Health, Welsh Office, Department of Health and Social Services (Northern Ireland), Scottish Home and Health Department. Heads of agreement. Ministerial group on junior doctors' hours. London: DoH, 1990 6 Joint Planning Advisory Committee. Report for the year 1989. London: DoH 1990:87.

\section{Correction}

Varicose veins

An editorial error occurred in this paper by $\mathrm{Mr}$ John $\mathrm{T}$ Hobbs (21 September, $p$ 707). The varicogram at the bottom of $p 709$ shows a perforating vein of the lower leg and should have appeared at the top of $p 710$ and that at the top of $p 710$ shows the saphenopopliteal junction with varix and should have appeared at the bottom of $\mathrm{p} 709$.

\section{A PAPER THAT CHANGED MY PRACTICE}

\section{Sympathetic common sense}

I have before me a reprint which is more than 20 years old. It is yellowing and beginning to tear at the folds. It has been read and reread. The article is by Lee G Miller and I have found it invaluable in my contacts with parents and caring staff of mentally handicapped children.

Miller mentions seven stages of normal family development and the stresses and rewards involved at each particular stage. A family with a retarded child is frozen at one of the early stages regardless of the age of the child and the ages of the parents. This alters the roles of the various members. Quoting Olshansky, whose works I have not had the opportunity to read, the author describes the reaction to the birth of a retarded child as a state of "chronic sorrow." The parents grieve for the normal child they had hoped to have while, simultaneously, they have to cope with the many needs of the retarded child. This may be an unrewarding task - a great deal of extra work without any obvious progress or even a smile as a reward.

The parents may not be equally affected or may be affected differently by this state of chronic sorrow. Some of the various reactions are described. We have probably all encountered these in our professional or private lives but may not have understood them.

The author describes three stages of parental adjustment:

- Shock, disorganisation, and denial. Little energy is left for coping with the immediate tasks
- Adjustment. A stage with contradictions where the parents may both accept and deny the child's retardation simultaneously and may search for a scapegoat and talk a great deal about themselves

- Reintegration or mature acknowldgement of the facts. Some parents never reach this stage.

In my experience progress through these stages has nothing to do with intelligence but is a form of emotional maturation.

Dr Miller concludes with some excellent advice about counselling parents, the developmental age of the child being more important than the intelligence quotient. Some parents have feelings of guilt and may find relief if they are able to talk about these.

This is a refreshing article about human feelings. There are no graphs, tables, diagrams, statistics, or questionnaires, just a great deal of sympathetic common sense in the handling of a neglected aspect of mental retardation. I have a special tip which I think is original. Ask the parents what they gave the child for his or her last birthday or Christmas present. If a 12 year old has been given a rattle then the parents really know something about his or her developmental level. - SHEILA BERGGREENretired physician in charge, Frederiksborg, Denmark

Miller LG. Towards a greater understanding of the parents of the mentally retarded child. Fournal of Pediatrics 1968;73:699-705. 